\title{
SCHWANN CELL PRECURSOR TRANSPLANT IN A RAT SPINAL CORD INJURY MODEL
}

Oscar de la Garza-Castro ${ }^{1}$, Herminia Guadalupe Martínez-Rodríguez ${ }^{2}$, Sandra Gabriela Sánchez-González ${ }^{1}$, Oscar Vidal-Torres ${ }^{1}$, Azalea ArReola-Romero ${ }^{2}$, OsCar de la Garza-Pineda ${ }^{1}$, Adriana Guadalupe Ancer-Arellano ${ }^{3}$, Santos GuZmán-López ${ }^{1}$, Rodrigo EnRiQue Elizondo-Omaña ${ }^{1}$

${ }^{1}$ Department of Human Anatomy, Microsurgery Laboratory, ${ }^{2}$ Department of Biochemistry and Molecular Medicine, and ${ }^{3}$ Department of Pathology, Facultad de Medicina, Universidad Autónoma de Nuevo León, N.L., Mexico

\begin{abstract}
Background: Differentiation of mesenchymal stem cells into Schwann cell precursors could reverse established lesions and sequelae of medullary transection. Objective: The objective of this study was to study the clinical response of mesenchymal stem cell transplantation with Schwann precursor cell transplantation in a rat spinal cord injury model, using motor function and histopathologic studies. Materials and Methods: A total of 28 Sprague-Dawley rats were randomly divided among four groups ( $n=7$ in each): sham group, control group, mesenchymal stem cell transplant group, and Schwann cell precursor transplant group. The surgical procedure was a laminectomy with transection of the spinal cord at the T11 level in the transplant groups and the injury control group. After 1 week, the transplant groups received stem cells directly in the injury site. Hind limb motor function was assessed using the locomotive scale of Basso, Beattie, and Bresnahan. 1 month after transplantation, all specimens were sacrificed to make a histopathologic description of sections taken from the site of injury and where stem cells were transplanted. Mean scores of mobility were compared using analysis of variance (ANOVA) of one factor with $95 \%$ reliability between groups and ANOVA of repetitive measures to evaluate evolution in the same group. Results: We observed that the control group had statistically greater mobility than the other groups $(p<0.0001)$ and that the group with spinal injury without treatment had the lowest mean mobility. The mobility score values from the Schwann cell precursor group were statistically higher than the group treated with mesenchymal stem cells $(p<0.0001)$. Conclusion: Schwann precursor cells had a greater effect on locomotive function than mesenchymal stem cells. (REV INVES CLIN. 2018;70:88-95)
\end{abstract}

Key words: Stem cell transplantation. Schwann cells. Spinal cord injury. Cell therapy. Spinal cord transection.

Corresponding author:

* Oscar de la Garza-Castro

Department of Human Anatomy

Microsurgery Laboratory

Facultad de Medicina

Universidad Autónoma de Nuevo León

Ave. Francisco I. Madero y Dr. Eduardo Aguirre

Col. Mitras Centro

C.P. 64460, Monterrey, N.L., Mexico

E-mail: delagarzacastro@hotmail.com

Received for publication: 18-12-2017

Accepted for publication: 16-02-2018

doi: $10.24875 / R I C .18002466$ 


\section{INTRODUCTION}

A spinal cord injury can cause the loss of motor and sensory function depending on the severity and site of the lesion ${ }^{1}$. Medullary trauma lesions depending on their extent and level, generate partial, or total disability. This can cause a social, labor, economic, and emotional impact, which can be permanent despite rehabilitation ${ }^{2}$.

It is estimated that the annual incidence of spinal cord injury in Mexico is 18.1 per million population. Spinal cord injuries occur most often in young men between 16 and 35 years of age. These lesions are usually a result of motor vehicle accidents (37\%), violence ( $28 \%)$, free falls $(21 \%)$, sports accidents ( $6 \%)$, and others $(8 \%)^{3}$. Spinal cord trauma is a medical emergency. The time that elapses between injury and treatment is critical in reducing comorbidities and sequelae and defines the final prognosis.

Scientific advances have allowed us to implement new research methods for the therapy of diseases that previously were treated but were considered incur$\mathrm{able}^{4}$. There are reports of procedures with promising results using neurotrophic factors, systems for intrathecal drug administration, biocompatible polymer implants, and stem cells and Schwann cell transplantation to regenerate and remyelinate the spinal cord 5 .

Differentiation of mesenchymal stem cells into Schwann cell precursors could reverse established lesions and sequelae of medullary transection. This could aid in emotionally and physically reincorporating into society patients suffering from this consequences ${ }^{6}$.

The objective of this study was to compare the clinical response of mesenchymal stem cell transplantation with Schwann precursor cell transplantation in a rat spinal cord injury model, using motor function and histopathologic studies.

\section{MATERIALS AND METHODS}

\section{Animals and experimental groups}

An experimental study of 28 Sprague-Dawley rats of both sexes (weighing approximately 250-300 g) was performed. The rats were provided by the animal care facility of the Embryology Department of the School of Medicine of the Universidad Autónoma de Nuevo León (UANL), which maintains adequate conditions such as relative humidity, dark-light cycle, food, and water ad libitum for the animals.

Four groups of seven specimens each were formed: Group 1 (sham group) in which only spinal cord laminectomy was performed to ensure that the damage was not caused by the surgery and to have an unharmed spinal cord; Group 2 (control group) in which the injured spinal cord did not receive any treatment to observe its natural course; Group 3 (transplant with mesenchymal stem cells), where the spinal cord was injured and transplanted with undifferentiated cells; and Group 4 in which Schwann precursor cells was transplanted following spinal injury.

The handling of animals was carried out according to the Official Mexican Norm of Care and Use of Laboratory Animals: NOM-062-ZOO-1999, Technical Specifications for the Production, Care and Use of Laboratory Animals. The study was approved by the Ethics Committee of the School of Medicine of the UANL with registration number $\mathrm{AH} 10-001$.

\section{Surgical procedure for spinal cord injury}

For surgical intervention, $1 \mathrm{mg}$ diazepam was administered intramuscularly and $5 \mathrm{mg}$ of ketamine as a general anesthetic per $100 \mathrm{~g}$ of weight in each rat. Once anesthetized, the operative area was shaved, and the animal was placed in a prone position on a Formica plate with the head fixed to apply the spacers used in the surgical procedure and the bands that hold the extended extremities and tail. After asepsis and antisepsis of the surgical area, a $3-\mathrm{cm}$ incision was made in the midline of the dorsal region extending from T8 to $L 2$ with a \#15 scalpel blade. Then, the muscles were dissected and separated to expose the spine. The spinous process was removed with a gouge, and laminectomy was performed on the T10-T11 level using a microsurgical drill (ECO 1000).

Spinal cord injury was performed in Groups 2-4. It consisted of a transection performed on a microscope (Carl Zeiss OPMI PICO) with a \#15 scalpel blade, involving the anterior and posterior cords. Bleeding was 
minimal and at the end of the procedure, the area was irrigated with saline, and the wound closed with nyIon 7-0 (Ethilon ${ }^{\circledR}$, Ethicon US, LLC). During the procedure, the specimen was placed on a thermal pad to maintain body temperature. The wound was cleaned with isodine and the specimen was placed in a cage under a heat lamp to keep it euthermic. After surgery, penicillin $\mathrm{G}$ procaine $40,000 \mathrm{IU}$ and $10 \mathrm{mg}$ of hydrocortisone were administered intramuscularly every $24 \mathrm{~h}$ for 4 days. Specimens were kept under observation and underwent bladder emptying maneuvers 3 times a day to ensure that they do not present urinary retention. They were given food and water ad libitum.

\section{Obtaining mesenchymal stem cells and Schwann cell precursors}

\section{Isolation of mesenchymal stem cells}

Cells were obtained from human adipose tissue from liposuction abdominal surgeries and processed immediately at the Biochemistry and Molecular Medicine Department Laboratory under strict aseptic conditions. The tissue was divided into small pieces with a scalpel, digested with collagenase Type I for $30 \mathrm{~min}$ and then centrifuged at 15,500 rpm for $5 \mathrm{~min}$. Cells were incubated for $72 \mathrm{~h}$ with $5 \% \mathrm{CO}_{2}$ at $37^{\circ} \mathrm{C}$ in $\alpha$-MEM medium supplemented with $10 \%$ fetal bovine serum (GIBCO/Invitrogen), $100 \mu \mathrm{g} / \mathrm{mL}$ of gentamicin, and $0.25 \mu \mathrm{g} / \mathrm{mL}$ of amphotericin B. After $72 \mathrm{~h}$, the cells that did not adhere to the culture dish were removed, fresh medium was added with the same characteristics and incubation continued until $80-90 \%$ confluence. Cells were replated to reach an approximate number of 2,00,000 cells per disc and frozen at $-80^{\circ} \mathrm{C}$ until use.

\section{Isolation of Schwann cell precursors}

Approximately 2,00,000 cells were seeded per disc in culture plates of six discs and incubated with $5 \% \mathrm{CO}_{2}$ at $37^{\circ} \mathrm{C}$. After $24 \mathrm{~h}$, they were transfected with plasmid pTracerCMV2-NT-3 using Lipofectamine TM 2000 (Invitrogen, Carlsbad, CA). Differentiation was carried out as follows: 1,00,000 cells were plated transfected to express neurotrophin- 3 in culture chambers of four discs in a $\alpha$-MEM medium supplemented with $10 \%$ fetal bovine serum (GIBCO/Invitrogen), $100 \mu \mathrm{g} / \mathrm{mL}$ gentamicin, and $0.25 \mu \mathrm{g} / \mathrm{mL}$ of amphotericin $B$, until they subconfluenced. Then, the medium was changed to $\alpha$-MEM supplemented with $1 \mathrm{mM}$ $\beta$-mercaptoethanol (BME, Sigma-Aldrich, Co., St, Louis, MO) without serum for $24 \mathrm{~h}$. After that time, it was changed to $\alpha$-MEM supplemented with $10 \%$ fetal bovine serum (GIBCO/Invitrogen), $100 \mu \mathrm{g} / \mathrm{mL}$ of gentamicin, $0.25 \mu \mathrm{g} / \mathrm{mL}$ of amphotericin $B$, and $0.1 \mathrm{mM}$ trans-retinoic acid (Calbiochem ${ }^{\oplus}$, Merck KGaA, Darmstadt, Germany). 3 days later, the medium was changed to $\alpha$-MEM supplemented with fetal bovine serum 10\%, forskolin 5 mM (FSK, Calbiochem, Merck KGaA, Darmstadt, Germany), 10 ng/mL beta-fibroblast growth factor (bFGF, Peprotech factor, Inc., Rocky Hill, NJ), $10 \mathrm{ng} / \mathrm{mL}$ of platelet-derived growth factor (PDGF, Peprotech EC Ltd., London, UK), and 200 ng/mL hergulina (HRG, Peprotech Inc.) cultivated for 8 days; at the end, the cells were frozen at $-80^{\circ} \mathrm{C}$ until use.

\section{Transplant}

One week after the surgical procedure, a total of $1,00,000$ stem cells in a $5 \mu \mathrm{L}$ gel solution were inoculated directly using a microsyringe into the site of injury with the same previously performed operative technique.

\section{Functional analysis}

The specimens were kept under observation for 1 month in which we continued with general care; furthermore, their cages were cleaned every 3 days to prevent infection. Weekly tests were conducted according to the Basso, Beattie, and Bresnahan (BBB) scale to evaluate motor function of the affected limb. This scale qualitatively measures voluntary movement at the joints of the hind limbs of rodents, in which the movements of hip, knee, and ankle consist of $22^{\circ}$; " 0 " represents no movement, and the score progressively increases with the movement of joints up to " 21 ," a level that reflects a normal gait. The time that it takes to progress to recovery from total paralysis to a level of movement depends on the resilience of the tested animal. For the assessment, each animal was video recorded for $2 \mathrm{~min}$ and two external examiners granted a functional score. 
Figure 1. Hematoxylin-Eosin histopathological staining of the spinal cord.

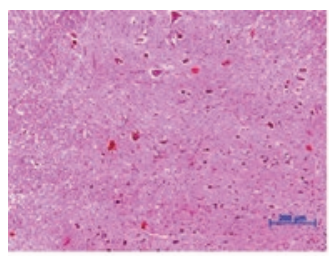

(A) Sham group.

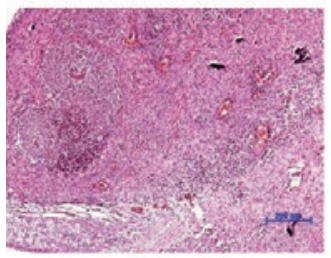

(C) Transplant with mesenchymal stem cells group.

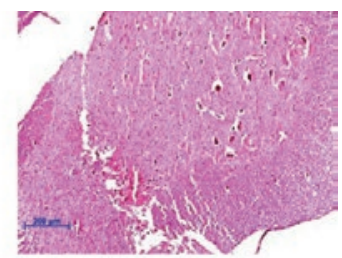

(B) Control group.

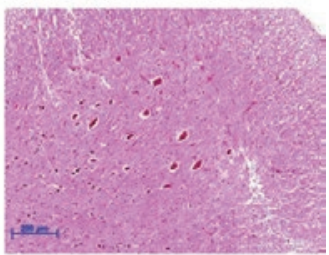

(D) Schwann's precursor stem cells group.
Figure 2. Luxol blue histopathological staining of the spinal cord.
(A) Sham group.

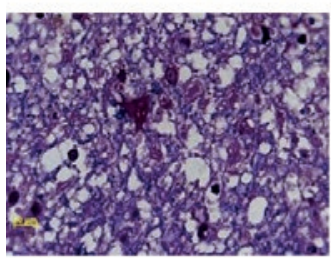

(C) Transplant with mesenchymal stem cells group.

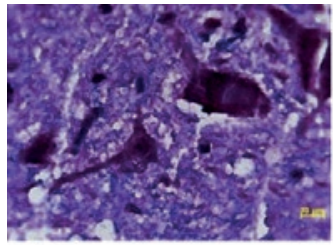

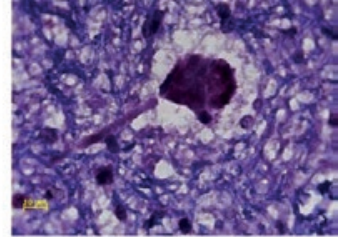

(B) Control group.

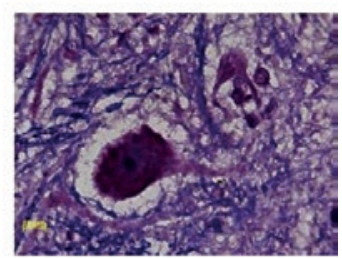

(D) Schwann's precursor stem cells group.

\section{Histological analysis}

At the end of the study, all the animals were sacrificed. Samples were obtained ( $<2 \mathrm{~cm}$ in length) from the lesion site in the spinal cord. Cross-sections were performed and were perfused in 10\% formaldehyde for fixation for $24 \mathrm{~h}$. The tissues were washed and dehydrated with absolute alcohol increases from $70 \%$ to $80 \%, 96 \%$ to $100 \%$, and xylene alcohol to finish. Inclusion in paraffin was performed and the tissue was then sectioned using microtome slices 4-5 $\mu \mathrm{m}$ and
Figure 3. Masson trichrome histopathological staining of the spinal cord.

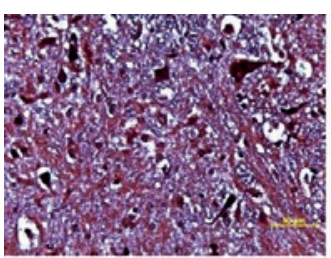

(A) Sham group.

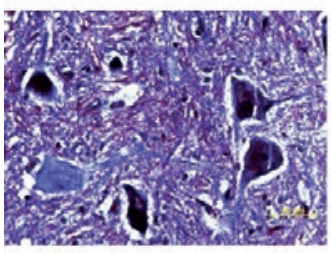

(C) Transplant with mesenchymal stem cells group.

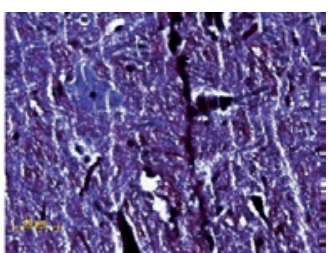

(B) Control group.

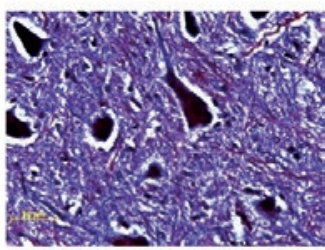

(D) Schwann's precursor stem cells group.
7-8 $\mu \mathrm{m}$ thick. The specimen was mounted on a slide and deparaffined for staining with hematoxylin and eosin to describe the general structure of the tissue (Fig. 1); blue Luxol was used to observe the percentage of demyelination (Fig. 2) and Masson's trichrome for fibrosis and scarring (Fig. 3). At the end, the slide was evaluated although the histopathologic analysis was blind until the end of the study.

\section{Statistical analysis}

The results were compiled in a Microsoft Office Excel ${ }^{\circledast}$ database for further analysis by the IBM SPSS Statistics $20^{\circledR}$ program. Descriptive statistics (mean and standard deviation) were performed, and groups were compared by analysis of variance (ANOVA) one factor and ANOVA of repetitive measures at reliability of $95 \%$. For all statistical analyses, $p$ values accepted as statistically significant were $\leq 0.05$.

\section{RESULTS}

The clinical, histopathologic, and statistical results were reviewed. The mean score, evaluated for 30 days after surgery, showed that before transplant a score of 0 was obtained, meaning that there was no movement in any of the inferior joints in the three study groups with spinal cord injury. 
Table 1. ANOVA of repetitive measures according to evaluations and group based on BBB scale

\begin{tabular}{|c|c|c|c|c|c|}
\hline Group & Week 1 & 2 & 3 & 4 & $p$ \\
\hline \multicolumn{6}{|l|}{ Sham } \\
\hline $\mathrm{N}$ & 7 & 7 & 7 & 7 & $\varepsilon$ \\
\hline Mean \pm SD & $20.43 \pm 0.535$ & $20.86 \pm 0.378$ & $21 \pm 0$ & $21 \pm 0$ & $\simeq-$ \\
\hline \multicolumn{5}{|l|}{ Control } & () \\
\hline $\mathrm{N}$ & 7 & 7 & 7 & 7 & \\
\hline Mean \pm SD & $0 \pm 0$ & $0 \pm 0$ & $0 \pm 0$ & $0 \pm 0$ & $\frac{-}{\omega}-$ \\
\hline $\begin{array}{l}\text { Mesenchymal stem cell } \\
\text { transplant }\end{array}$ & & & & & $\frac{\underline{\underline{c}}}{\underline{\underline{\underline{n}}}}$ \\
\hline $\mathrm{N}$ & 7 & 7 & 7 & 7 & 르 \\
\hline Mean \pm SD & $0.14 \pm 0.378$ & $0.71 \pm 0.488$ & $1.71 \pm 0.488$ & $1.86 \pm 0.378$ & $<0.001$ \\
\hline $\begin{array}{l}\text { Schwann cell precursors } \\
\text { transplant }\end{array}$ & & & & & $\begin{array}{ll}4 \\
0 \\
\frac{1}{6}\end{array}$ \\
\hline $\mathrm{N}$ & 7 & 7 & 7 & 7 & $\frac{\mathrm{o}}{\mathrm{n}}$ \\
\hline Mean \pm SD & $0.71 \pm 0.488$ & $2.86 \pm 0.378$ & $5.86 \pm 0.378$ & $8.86 \pm 0.378$ & $<0.001$ \\
\hline
\end{tabular}

$\mathrm{N}$ : 28 rats; SD: standard deviation; BBB: basso, beattie, and bresnahan.

Table 2. General descriptive analysis according to group based on BBB scale

\begin{tabular}{llcl}
\hline Group & N & Mean \pm SD & $20.82 \pm 0.390$ \\
\hline Sham & 7 & $0.00 \pm 0.000$ & \pm \\
Control & 7 & $1.11 \pm 0.832$ & 5 \\
Mesenchymal stem cell transplant & 7 & $4.57 \pm 3.156$ & $\vdots$ \\
Schwann cell precursors transplant & 7 & 5 \\
\hline
\end{tabular}

$\mathrm{N}$ : 28 rats; SD: standard deviation; BBB: basso, Beattie, and Bresnahan.

In Group 1, in the $1^{\text {st }}$ week, a slight instability was observed that gave a score of 20 on the BBB scale, perhaps due to a physiological and inflammatory reaction caused by the surgical procedure; however, in the $2^{\text {nd }}$ week, the specimens recovered motor function with a normal gait. In Group 2, a score of zero was maintained throughout the study period, showing a minimum tendency for recovery, using this group as a baseline to assess the natural course of the injury without cell transplantation. Group 3 received at the $1^{\text {st }}$ week, a score of zero, similar to the other groups, but during the $2^{\text {nd }}$ week, a limited extension movement of the hip joint was observed, giving this group a score of 1 and a score of 2 by the $3^{\text {rd }}$ week. Group 4 showed a faster recovery, obtaining after the $1^{\text {st }}$ week a score of 1 , after the $2^{\text {nd }}$ week a score of 3 , in the $3^{\text {rd }}$ week a score of 6 , and by the end of the month a score of 9 .

In the histopathological study on the lesion site of the spinal cord, morphological changes were assessed with hematoxylin and eosin (Fig. 1), Luxol blue (Fig. 2), and Masson's trichrome staining (Fig. 3). The specimens in Group 1 with a diameter of $0.3 \mathrm{~cm}$ showed no evidence of fibrosis or demyelination, only mild areas of pyknosis (Figs. 1A, 2A, 3A). Specimens in Group 2 with a diameter of $0.2-0.4 \mathrm{~cm}$ showed no demyelination, inflammation, or fibrosis (Figs. 1B, 2B, 3B). Specimens of Group 3, with a diameter of $0.2-0.5 \mathrm{~cm}$, showed severe acute and chronic inflammation with bleeding and new blood vessels in formation, high fragmentation and demyelination of $40-45 \%$, and high fibrosis up to $30 \%$ (Figs. $1 \mathrm{C}, 2 \mathrm{C}, 3 \mathrm{C}$ ). Specimens in Group 4, with a diameter of 0.2-0.4 cm, had mild chronic inflammation fragmentation with focal demyelination of $0-30 \%$, and mild fibrosis up to $10 \%$ (Figs. 1D, 2D, 3D).

The four groups of rats were analyzed, evaluating their mobility per week according to the BBB scale (Table 1 ). In the general evaluation of the groups (Table 2), the sham groups, without a lesion, showed 
full mobility mean values ( $20.82 \pm 0.39$ ), and in the control group with spinal cord lesion, there was a total absence of mobility.

When means were compared by ANOVA of one factor at a reliability of $95 \%$, we found that the mean mobility of the control group was statistically greater than that of the other groups $(p<0.0001)$. The control group with injury had less mobility than the other groups; however, when the results of mobility between the groups with mesenchymal stem cell transplant and Schwann precursor cell transplant were compared, the latter group showed statistically significant values $(p<0.0001)$.

\section{DISCUSSION}

Currently, there are no reports of a successful treatment to restore function after spinal cord injuries that partially or completely disable the individual, due to their complexity.

It has been demonstrated that restoration of motor functions is associated with gene expression and secretion of neurotrophic factors such as neurotrophin-3 and brain-derived neurotrophic factor, which induce oligodendrocyte proliferation to promote growth and axon regeneration at the site of the injury to restore nerve conduction through remyelination ${ }^{7,8}$.

Cell therapies in the central nervous system include replacing cells lost to injury with cells derived from an outside source. These have the advantage of integrating into the injury site, restoring the lost neural circuits, and promoting neuronal plasticity ${ }^{9-11}$. However, among the obstacles are the obtention of these cells and their reproducibility in cell culture systems.

In recent years, the use of embryonic stem cells differentiated into neural precursors has helped reduce chronic pain and restore sensory and motor function after a spinal cord injury in rats with complete section, reaching a score of 12.5 on the $B B B$ scale ${ }^{12,13}$.

Subsequently, the use of mesenchymal stem cells in multiple murine assays has been shown to control the inflammatory process after injury, by inducing the production of neuroprotective factors that promote neuronal survival with consequent improvement in motor function $2,14,15$.

The use of Schwann cells in cell transplantation has shown that they can establish and maintain nodes of Ranvier in axons, improving the process of remyelination for up to 1 year, managing to restore the properties of nerve conduction to almost a normal degree ${ }^{16,17}$.

In this study, we used the technique described by Jiang et al. to differentiate mesenchymal stem cells into progenitor Schwann cells and compared their therapeutic potential with mesenchymal stem cells ${ }^{18}$.

A rat model with spinal cord injury was used to examine the effect of stem cells after surgery and the BBB scale to assess the progress of the specimens. Young Sprague-Dawley rats of both sexes were employed in our study as it has been found in previous studies assessing the effects of sex on central nervous system remyelination that in young adult animals, there was no difference in remyelination at 4 weeks after lesion induction in males or females. However, in older adult rats, the extent of oligodendrocyte remyelination was significantly lower in males compared with the females at 8 weeks after lesion induction. These results indicate a sex-associated divergence in remyelination efficacy that occurs more according to the aging of the animals than in relation to the sex steroid hormones ${ }^{19}$.

In our study, Group 1 (without spinal cord injury) showed a slight motor deficit during the $1^{\text {st }}$ week after the procedure but after a month had a complete recovery of gait. Group 2, in which spinal cord injury was performed but without cell transplantation, the score at the end of the 4 weeks of assessment remained the same with no improvement in gait, unlike the group that received transplanted mesenchymal stem cells (Group 3) and Schwann precursor cells (Group 4), where the mean scores in the $4^{\text {th }}$ week were $1.86 \pm 0.3$ and $8.86 \pm 0.3$, respectively.

Dasari et al. used the same BBB scale to assess motor function. They reported that all injured rats showed severe locomotor deficits 1 day after surgery and compared a group of injured rats without experimental treatment (mean score of $5.04 \pm 0.2$ ) against a 
group of rats treated with stem cells showing a mean score of $12.95 \pm 0.15,14$ days after surgery. This difference with our study could be due to the use of a weighted impact device to produce the spinal injury in their study ${ }^{8}$.

Another study by Dagci et al. reported at 28 days, a decreased BBB score (0-2) in the group of spinal cord hemisection, and in the embryonic stem cells transplantation group, a mean score of $11.2 \pm 2.9$ similar to the results in our study for the group with Schwann precursor cells $(8.86 \pm 0.3)^{20}$. It was found that even when differentiating stem cells to oligodendrocytic progenitors, motor function was improved by limiting the inflammatory response, and remyelination was stimulated. A study of 2015 described a murine model of complete spinal cord transection with an oligodendrocyte transplant in which a functional motor recovery in the hind limb rose to a mean score of 6 after 4 months $^{21}$.

Based on our histological studies (each with three distinct and specific nerve tissue staining), clinical results with the histopathologic data showed a significant change in fibrosis, demyelination, and inflammation between the group of mesenchymal stem cells and Schwann precursor cells. Specimens transplanted with Schwann precursor cells showed less tissue damage, no evidence of acute inflammation, minimal fibrosis and decreased demyelination in the spinal cord, resulting in a better adaptation of this cell type in the nervous tissue, compared to the mesenchymal stem cell group.

No study has used, in rats, neurotrophin-3 to differentiate stem cells into Schwann cells as was done in our study. This technique reduces the likelihood of graft rejection in nerve tissue. Most of the studies administer the cell transplant into the injury; however, the use of biomaterial templates, direct electric stimulation, and stem cell gene modification (mesenchymal or Schwann cell precursors) can prove to be a new and better way to improve functional recovery after a spinal cord injury ${ }^{22,23}$.

One of the limitations of our study was that, although we used NT-3 to differentiate Schwann cells precursors as other studies have done, we were not able to do the analysis to confirm the expression of this factor on our Schwann cells precursors.
Our study showed that the injured rats that received no treatment had paralyzed hind limbs, pushing their way with their forelimbs. Rats with mesenchymal stem cell transplantation had limited movement, but rats that received Schwann precursor cells had greater coordination and movement, and a faster recovery. This indicates that cell transplantation promotes functional recovery in animals, which provides important data to the field of spinal cord injury.

\section{ACKNOWLEDGMENTS}

We would like to thank Sergio Lozano-Rodriguez, M.D., and Alejandro Quiroga-Garza, M.D. for their help in the editing of this manuscript.

\section{REFERENCES}

1. National Institute of Neurological Disorders and Stroke. "Spinal Cord Injury: Hope Through Research", NIH Publication No. 13160, July 2013. Available from: https://www.ninds.nih.gov/ Disorders/Patient-Caregiver-Education/Hope-Through-Research/Spinal-Cord-Injury-Hope-Through-Research.

2. Park WB, Kim SY, Lee SH, Kim HW, Park JS, Hyun JK. The effect of mesenchymal stem cell transplantation on the recovery of bladder and hindlimb function after spinal cord contusion in rats. BMC Neurosci. 2010;11:119.

3. Center NSCIS. Spinal Cord Injury Facts and Figures at a Glance. Birmingham, Alabama: national Spinal Cord Injury Statistical Center; 2013. Available from: National Spinal Cord Injury Statistical Center, Facts and Figures at a Glance. Birmingham, AL: University of Alabama at Birmingham, March 2013. Available from: https://www.nscisc.uab.edu/PublicDocuments/fact_figures_docs/Facts\%202013.pdf.

4. Roh $\bar{D}$, Seo MS, Choi HS, et al. Transplantation of human umbilical cord blood or amniotic epithelial stem cells alleviates mechanical allodynia after spinal cord injury in rats. Cell Transplant 2013;22:1577-90.

5. Willerth SM, Sakiyama-Elbert SE. Cell therapy for spinal cord regeneration. Adv Drug Deliv Rev. 2008;60:263-76.

6. Lee KH, Suh-Kim H, Choi JS, et al. Human mesenchymal stem cell transplantation promotes functional recovery following acute spinal cord injury in rats. Acta Neurobiol Exp (Wars). 2007;67:13-22.

7. Razavi S, Ghasemi N, Mardani M, Salehi H. Remyelination improvement after neurotrophic factors secreting cells transplantation in rat spinal cord injury. Iran J Basic Med Sci. 2017;20:391-8.

8. Dasari VR, Spomar DG, Cady C, et al. Mesenchymal stem cells from rat bone marrow downregulate caspase-3-mediated apoptotic pathway after spinal cord injury in rats. Neurochem Res. 2007;32:2080-93.

9. Zhang $\mathrm{H}$, Wang L, Wen $\mathrm{S}$, et al. Magnetic resonance imaging tracing and assessing repair function of the bone marrow mesenchymal stem cells transplantation in a rat model of spinal cord injury. Oncotarget. 2017;8:58985-99.

10. Konig N, Trolle C, Kapuralin K, et al. Murine neural crest stem cells and embryonic stem cell-derived neuron precursors survive and differentiate after transplantation in a model of dorsal root avulsion. J Tissue Eng Regen Med. 2017;11:129-37.

11. Min J, Kim JH, Choi KH, Yoon HH, Jeon SR. Is there additive therapeutic effect when GCSF combined with adipose-derived stem cell in a rat model of acute spinal cord injury. J Korean Neurosurg Soc. 2017;60:404-16

12. Ruzicka J, Machova-Urdzikova L, Gillick J, et al. A comparative study of three different types of stem cells for treatment of rat spinal cord injury. Cell Transplant. 2017;26:585-603. 
13. Barros Filho TE, Molina AE. Analysis of the sensitivity and reproducibility of the basso, beattie, bresnahan (BBB) scale in wistar rats. Clinics (Sao Paulo). 2008;63:103-8.

14. Zhao $Y$, Tang $F$, Xiao $Z$, et al. Clinical study of NeuroRegen scaffold combined with human mesenchymal stem cells for the repair of chronic complete spinal cord injury. Cell Transplant. 2017:26:891-900

15. Wang KK, Zhang Z, Moghieb A. Biomarkers for CNS injury and regeneration. In: So KF, Xu XM, editors. Neural Regeneration. London: Elsevier Science; 2015. p. 401-10.

16. Anderson KD, Guest JD, Dietrich WD, et al. Safety of autologous human schwann cell transplantation in subacute thoracic spinal cord injury. J Neurotrauma. 2017;34:2950-63.

17. Lu $P$, Ceto $S$, Wang $Y$, et al. Prolonged human neural stem cell maturation supports recovery in injured rodent CNS. J Clin Invest. 2017;127:3287-99.

18. Jiang L, Zhu JK, Liu XL, Xiang P, Hu J, WH. Y. Differentiation of rat adipose tissue-derived stem cells into Schwann-like cells in vitro. Neuroreport. 2008;19:1015-9.
19. Li WW Penderis ], Zhao C, Schumacher M, Franklin RJ. Females remyelinate more efficiently than males following demyelination in the aged but not young adult CNS. Exp Neurol. 2006;202:250-254.

20. Dagci T, Armagan G, Konyalioglu S, Yalcin A. Alterations in the expression of the apurinic/apyrimidinic endonuclease-1/Redox Factor-1 (APE/Ref-1) and DNA damage in the caudal region of acute and chronic spinal cord injured rats treated by embryonic neural stem cells. Physiol Res. 2009;58:427-34.

21. Lukovic D, Moreno-Manzano V, Lopez-Mocholi E, et al. Complete rat spinal cord transection as a faithful model of spinal cord injury for translational cell transplantation. Sci Rep. 2015;5:9640.

22. Bonilla C, Otero L, Aguayo C, Rodríguez A, Zurita M, Vaquero Crespo J. Estudio de la utilidad del gel de fibrina como soporte celular en el trasplante intracerebral de células madre mesenquimales. Trauma Fund MAPFRE. 2009:20:243-8.

23. Ronsyn MW, Daans J, Spaepen G, et al. Plasmid-based genetic modification of human bone marrow-derived stromal cells: analysis of cell survival and transgene expression after transplantation in rat spinal cord. BMC Biotechnol. 2007;7:90. 